\title{
Evaluation of the Effectiveness of Polyphenols from Grape and Apple Combined with Saffron on Erectile Function: An Observational Study
}

\author{
F Allaert ${ }^{1}$, D Guillemet ${ }^{2}$, R Schueller ${ }^{1}$ and F Herpin ${ }^{1 *}$ \\ ${ }^{1}$ Chair of health evaluation at BSB \& CEN Nutriment, 1 impasse Francoise Dolto, France \\ ${ }^{2}$ Nexira, 129 Chemin de Croisset Rouen, France
}

${ }^{*}$ Corresponding author: F Herpin, Chair of health evaluation at BSB \& CEN Nutriment, 1 impasse Francoise Dolto, France.

Received Date: May, 08, 2021

Published Date: July 28, 2021

\section{Abstract}

Background: Preclinical studies suggest that a synergistic polyphenols extract combined with Saffron (EnoSTIM ${ }^{\mathrm{TM}}$ ) could help to reduce the decrease in erectile function resulting from an alteration of microcirculation linked to age, vascular inflammation, and oxidative stress.

Methods: Observational study conducted on men aged between 45 and 65, complaining of a decline in their erectile function and having a daily consumption of EnoSTIM ${ }^{\mathrm{TM}}(600 \mathrm{mg} /$ day) over 28 days. Data were recorded daily to describe the quality of each erection-on-Erection Hardness Scale (EHS). IIEF-5 (International Index of erection) has been also assessed for the last month before and during administration period.

Result: 94 men with 53.4 years mean age were included in the study. EHS increased significantly to $3.3+/-0.6$ percentage points representing an improvement of $+22 \%$ and a positive impact was observed in $73.8 \%$ of subjects. The average percentage of erections during which the penis was hard enough for penetration increased significantly from $68.0 \%$ to $87.7 \%$ while the average percentage of erections where the penis was not hard enough for penetration decreased by $32.1 \%$ to $12.3 \%$ ( $\mathrm{p}<0.0001$ ). IIEF-5 and satisfaction criteria have also been significantly improved.

Conclusion: The intake of EnoSTIM ${ }^{\mathrm{TM}}$ increases the quality of erection and especially its rigidity. This effect on the hardness of erections is related to an improvement of vascular health status and the vasoactive action of nitrous oxide whose synthesis is increased by EnoSTIM ${ }^{\mathrm{TM}}$.

Keywords: Flavonoids; Polyphenols; Saffron; Erection

\section{Introduction}

Thirty-five to fifty-two percent of men are affected by a decline in sex function beyond the age of 40 , particularly by a decrease in erectile function resulting from an alteration of microcirculation linked to age and vascular inflammation, but also oxidative stress [1-3]. In the absence of an abnormality inhibiting vascular flow at the level of arterial trunks, decline in erectile function is in fact strongly linked to a lack of bioavailability of nitrous oxide (NO) which by its vasodilatory activity improves the filling of corpora cavernosa with blood [4]. This explains that for many men, the main

problem they face is not the frequency of their erections, but their quality and specifically their hardness for which NO plays a major role.

Oxidative stress participates in altering the quality of the erection and an excess of oxidative stress can play a significant role in reducing sex function [5]. Free radicals and specifically the superoxide radical is very reactive and form peroxynitrite with NO which diminishes the NO bioavailability by shortening its duration. In other words, the superoxide and peroxynitrite radicals could 
be involved in the negative regulation of NO synthase in the penis and thus directly contribute to the decline of erectile function [6,7]. This co-symptomatology simultaneously linked to age, erection troubles and early symptoms of cardiovascular disease has long been observed and today erectile decline is considered as a preliminary and early warning symptom of significant and chronic oxidative deviation and vascular inflammation leading to changes in endothelial function (such as the synthesis of NO) and the rigidification of vessel walls toward diseases of the atherosclerosis variety $[3,8]$.

To obtain optimal influence on the production of NO and fight against the effects of oxidative stress, Nexira has developed an exclusive specific combination of flavonoids from grapes and polyphenols from apples called NPF. NPF was the object of a clinical study which observed its effect on the modulation of initial vascular inflammation markers of the chemokine type on at-risk individuals after 4 weeks of treatment [9]. In an effort to attend seek an effect on the quality of erections, NPF was paired with saffron which multiple studies have shown to be capable of improving sexual function [1012] shown by improvements in the IIEF-5 (International Index of Erectile Function) from 30 to $56 \%$.

Current preclinical data show that NPF and saffron display synergistic active mechanisms: NPF would influence enzyme activation of the endothelial NO synthase by phosphorylation of serine 1177 while saffron would increase the expression of the RNA of this enzyme concentration [13]. The synergistic effect of these 2 ingredients on the secretion of NO was confirmed while working with endothelial cells [14]. To continue to investigate these preclinical test results, a pilot study was held to evaluate the effect of EnoSTIM ${ }^{\mathrm{TM}}$ on sexual function and erection quality in men with complaints of their decline.

\section{Materials and Methods}

Table 1: Synoptic table.

\begin{tabular}{|c|c|c|c|c|c|}
\hline Evaluation Criteria & Inclusion (Before D-7) & D0 & D1 & D14 & D28 \\
\hline Erection Hardness Scale (Replicable Questionnaire) & \multicolumn{2}{|c|}{ Grading for each new erection between D-7-D0 and between D1-D28 } \\
\hline Erection Hardness Scale & $\mathrm{X}$ & $\mathrm{X}$ & $\mathrm{X}$ & $\mathrm{X}$ & $\mathrm{X}$ \\
\hline Erection frequency & $\mathrm{X}$ & $\mathrm{X}$ & $\mathrm{X}$ & $\mathrm{X}$ \\
\hline Spontaneous erections frequency & $\mathrm{X}$ & & $\mathrm{X}$ & $\mathrm{X}$ \\
\hline IIEF-5 & $\mathrm{X}$ & & $\mathrm{X}$ \\
\hline PGII (Erection Quality) & & & & $\mathrm{X}$ \\
\hline PGII (Sex Life) & & & & $\mathrm{X}$ \\
\hline Opinion and satisfaction & & & \\
\hline Observation & & & \\
\hline
\end{tabular}

The main objective of this pilot study based upon a model of observational design, carried out in a center for clinical investigation (CEN Nutriment) was to evaluate the effect of a daily consumption of EnoSTIM $^{\mathrm{TM}}$ (600 mg/day) over 28 days on the quality of erections. One of the characteristics of this study was to use the smartphone application $\left(\right.$ Nurstrial $\left.^{\otimes}\right)$ to report in real time the quality of each erection by the EHS or "Erection Hardness Grade Scale" 15 to avoid the bias of memory that often compromises the quality of studies in this field when data is gathered after the fact. The security measures of this application received the approval of the French Data Protection Authority (CNIL) (DR-2015-699). The subjects must have given written informed consent to be include. The secondary objectives were to evaluate more comprehensively the effect of EnoSTIM ${ }^{\mathrm{TM}}$ on their sexual function through the International Index of Erectile Function (IIEF-5), the subjective opinions of subjects on their improvement through the PGII questionnaire (Patient Global Improvement Impression), their current satisfaction with their sex life and the gains made by EnoSTIM ${ }^{\mathrm{TM}}$ through Lickert scales. The study was carried out on men between 45 and 65 years of age, with complaints of a decline in their sexual function characterized by an Erection Hardness Score (EHS) between 2 and 3 at least over the course of the previous month. According to the EHS classification, grade 1 corresponds to a penis that is enlarged but not hard, grade 2 to a penis that is hard but insufficient to allow penetration, stage 3 to a penis sufficiently hard to allow penetration but not entirely rigid, stage 4 to a penis that is entirely rigid. In order to avoid any modifications to observation conditions, no non-inclusion criteria were considered except for known allergies to product ingredients, specifically grape, apple, saffron and sulfites. Subjects on antidepressant or vasodilatory treatments or taking a treatment against erectile dysfunction were also excluded. The progress of the study and the evaluation criteria are summarized in table 1.

\section{Population Studied}

Among the 103 men initially included in the study, 94 (91.3\%) filling all inclusion criteria, not meeting a single exclusion criterium, and having correctly used the Nurstrial ${ }^{\circledR}$ application to collect their data, remained in the study until the end and were included in the statistical analysis. 
Among these, $42.6 \%$ were between 45 and 50 years old $34.0 \%$ between 50 and 60 years old, and $23.4 \%$ were over 60 . Nearly two thirds of them $(61.7 \%)$ were overweight $\left(25-30 \mathrm{~kg} / \mathrm{m}^{2}\right.$; $48.9 \%$ ) or obese $\left(>30 \mathrm{~kg} / \mathrm{m}^{2} ; 12.8 \%\right)$. Nearly all $(94.7 \%)$ were in a relationship or had a sexual partner and most of them played a sport or participated in a physical activity: 1 to $2 \mathrm{hr} /$ week (26.6\%), $>2 \mathrm{hr} /$ week (41.5\%), and $>10 \mathrm{hr}$ a week $(11.7 \%)$.

Three quarters of them (76.6\%) maintained a current libido, all $(100 \%)$ had had sexual activity during the last 4 weeks (alone or not) but $39.4 \%$ experienced a decrease in erection quality within the last year and $60.6 \%$ within the last 1 to 5 years.

According to the IIEF- 5 score, the decline in erectile function was moderate to severe in $11.8 \%$ of them, slight to moderate in $43.6 \%$, slight to none in $43.6 \%$. As expected for the study, the reduction of their sexual function before the inclusion, was not characterized by a strong reduction in the frequency of their erection: nearly two thirds among them (61.7\%) had at least three or more per week and $22.4 \%$ had frequent or relatively frequent spontaneous erections. In contrast, their complaints were primarily about the quality of their erections: $23.4 \%$ said that their penis was hard but not enough for penetration, $76.6 \%$ that they were hard enough for penetration but not completely hard, and none among them responded that it was entirely rigid. The average EHS score was 2.7 \pm 0.5 out of an optimal score of 4 . These men took EnoSTIM ${ }^{\mathrm{TM}}$ over 28 days, described each erection on the Nurstrial ${ }^{\circledR}$ application and filled questionnaires out at D14 and D28 evaluating their sexual function and their opinion on the effect of the product.

\section{Improvement in Sexual Decline}

The EHS which was the primary endpoint and had significantly and progressively increased over the whole duration of the reporting (Figure 1) reached $3.3 \pm 0.6$ points at the end of the study which marks a $+22 \%$ ( $+0.6 \pm 0.5$ points) improvement and a positive change was observed in $73.8 \%$ of subjects. The average score from the month preceding the recorded baseline in the fixed questionnaire was 2.77 and was close in comparison to the baseline recorded in the replicable questionnaire. Taking hardness scale into account, the average percentage of erections during which the penis was hard enough for penetration (hardness 3 and 4) increased progressively and significantly from $68 \%$ before taking EnoSTIM $^{\mathrm{TM}}$ to $87.7 \%$ during the 4 th week of reporting while the average percentage of erections during which the penis wasn't hard enough for penetration decreased from $32.1 \%$ to $12.3 \%$ ( $p<0.0001$ ). Furthermore, the average percentage of erections during which the penis was entirely hard (hardness 4) increased progressively and significantly from $9.9 \%$ to $44.8 \%$ (Figure 2 ).

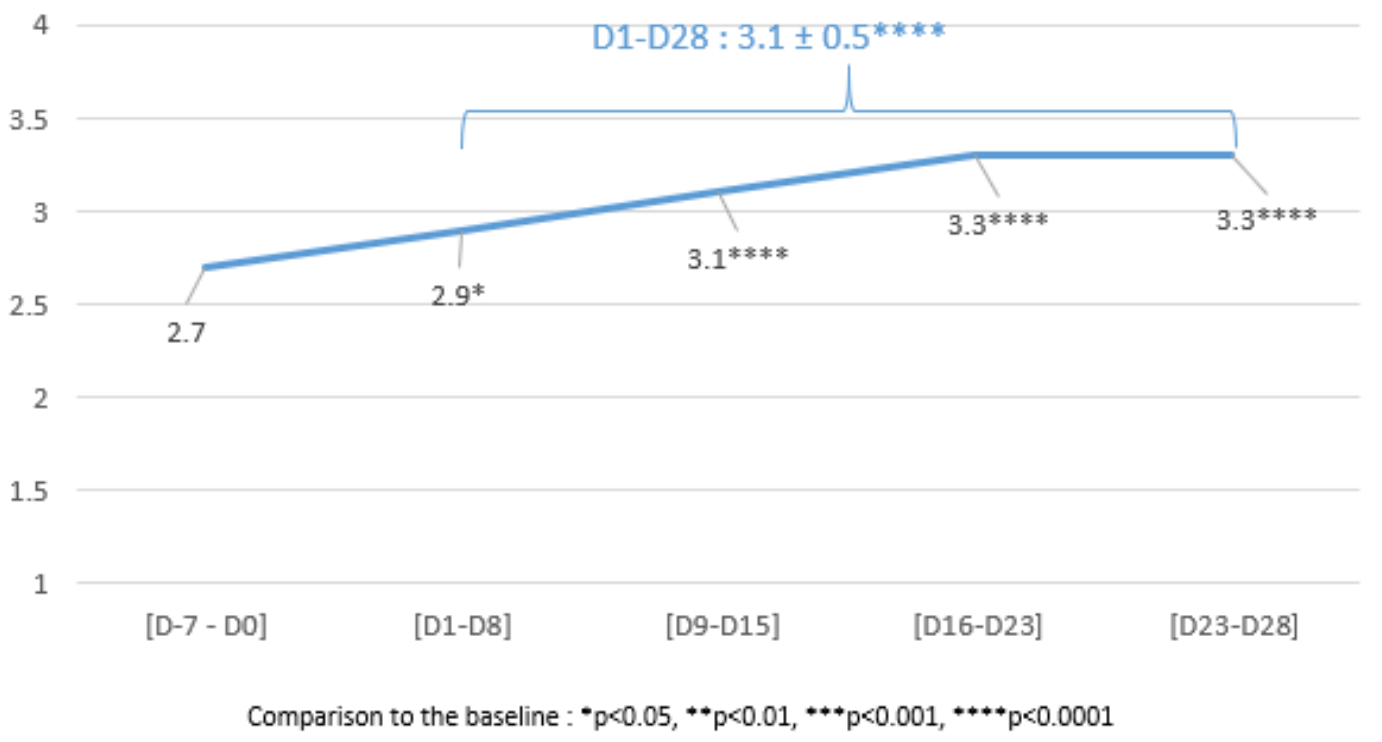

Figure 1: Average Evolution of EHS in 28 Days.

The total number of erections and the number of spontaneous erections also increased. The percentage of men having more than 4 erections per week went from $20.0 \%$ to $36.5 \%$ while the percentage of those having 2 erections or less per week decreased from $38.8 \%$ to $17.7 \%$ (p: 0.0017 ) (Figure 3). In addition, the percentage of men feeling spontaneous erections more than once every other day or nearly every day, significantly increased from $21.2 \%$ at the outset to $31.7 \%$ at D14 and $31.8 \%$ at D28, while the percentages of those having erections rarely or nearly not at all reduced from $47.0 \%$ to $30.6 \%$ at D14 and D28 (p: 0.0116) (Figure 4). 


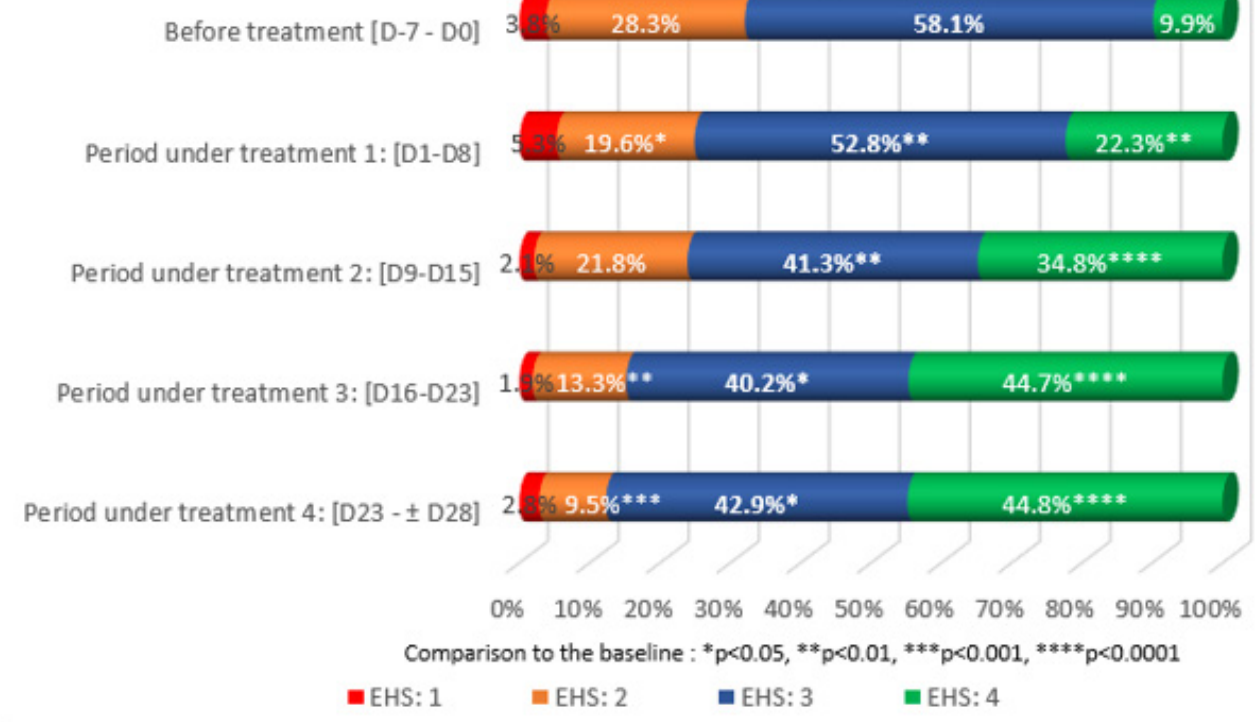

Figure 2: Evolution of EHS Scores.

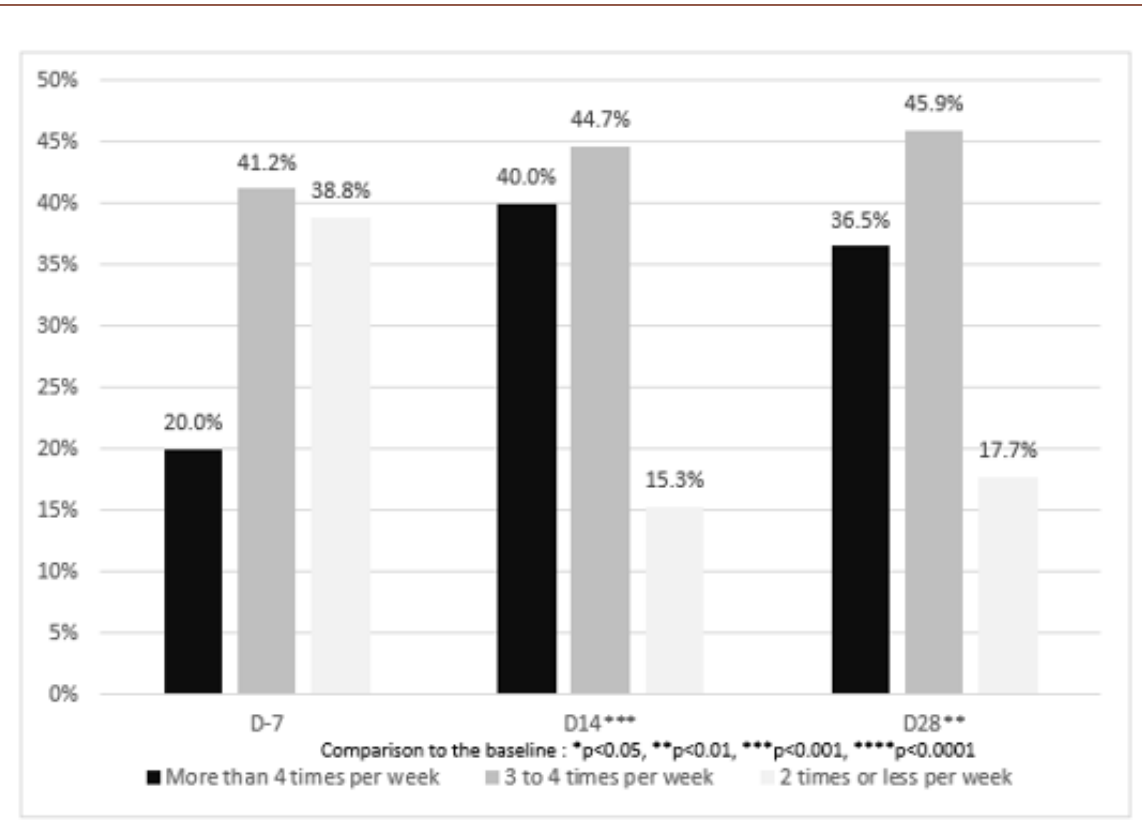

Figure 3: Evolution of the frequency of erections.

Table 2: Inclusion Characteristics.

\begin{tabular}{|c|c|}
\hline \multicolumn{1}{|c|}{ Inclusion Characteristics } \\
\hline Age & $53.4 \pm 6.8$ years \\
\hline$[40-50]$ years & $\mathrm{n}=40(42.6 \%)$ \\
\hline$[50-60]$ years & $\mathrm{n}=32(34.0 \%)$ \\
\hline 60 years or more & $\mathrm{n}=22(23.4 \%)$ \\
\hline BMI & $26.3 \pm 3.1 \mathrm{~kg} / \mathrm{m}^{2}$ \\
\hline Normal $\left(18.5-25 \mathrm{~kg} / \mathrm{m}^{2}\right)$ & $\mathrm{n}=40(42.6 \%)$ \\
\hline Overweight $\left(25-30 \mathrm{~kg} / \mathrm{m}^{2}\right)$ & $\mathrm{n}=32(34.0 \%)$ \\
\hline Obese $\left(>30 \mathrm{~kg} / \mathrm{m}^{2}\right)$ & $\mathrm{n}=22(23.4 \%)$ \\
\hline
\end{tabular}




\begin{tabular}{|c|c|}
\hline Less than a year & $\mathrm{n}=37(39.4 \%)$ \\
\hline Between 1 and 5 years & $\mathrm{n}=57(60.6 \%)$ \\
\hline Subjects in relationship or with sexual partner(s) & $\mathrm{n}=89(94.7 \%)$ \\
\hline Preserved libido & $\mathrm{n}=72(76.6 \%)$ \\
\hline \multicolumn{1}{|c|}{ Sports or Physical Activity (Hours Per Week) } \\
\hline 0 to $1 \mathrm{hr} /$ week & $\mathrm{n}=19(20.2 \%)$ \\
\hline 1 to $2 \mathrm{hr} /$ week & $\mathrm{n}=25(26.6 \%)$ \\
\hline$>2 \mathrm{hr} /$ week & $\mathrm{n}=39(41.5 \%)$ \\
\hline$>10 \mathrm{hr} /$ week & $\mathrm{n}=11(11.7 \%)$ \\
\hline
\end{tabular}

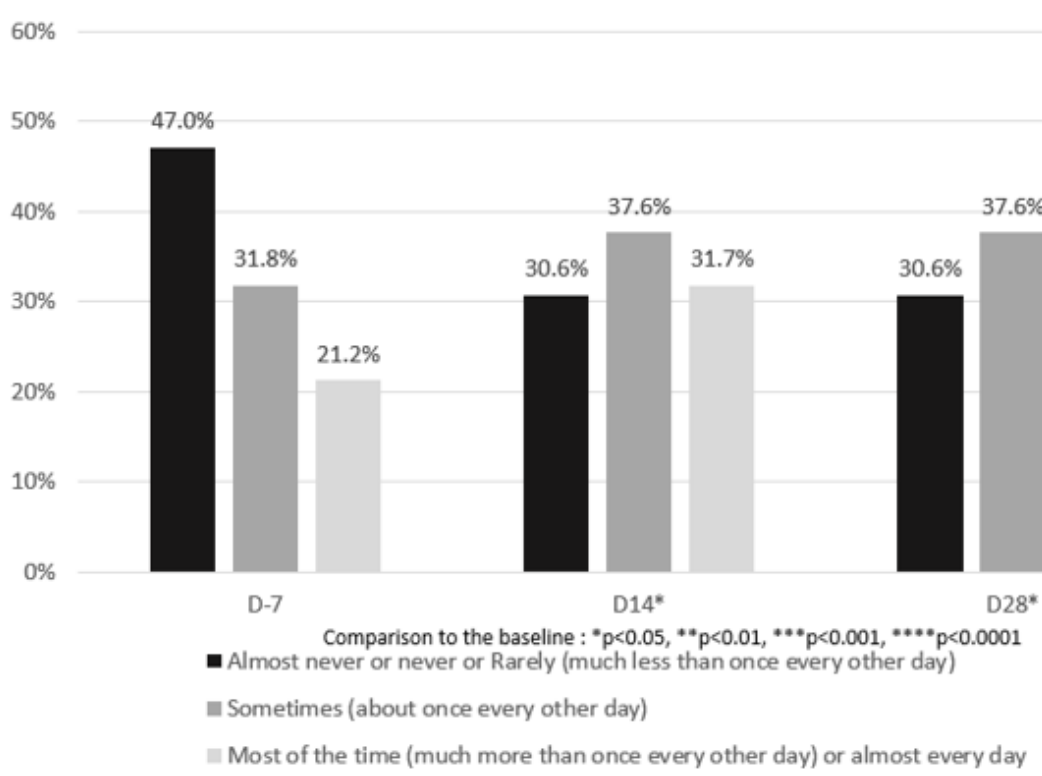

Figure 4: Evolution of the frequency of spontaneous erections.

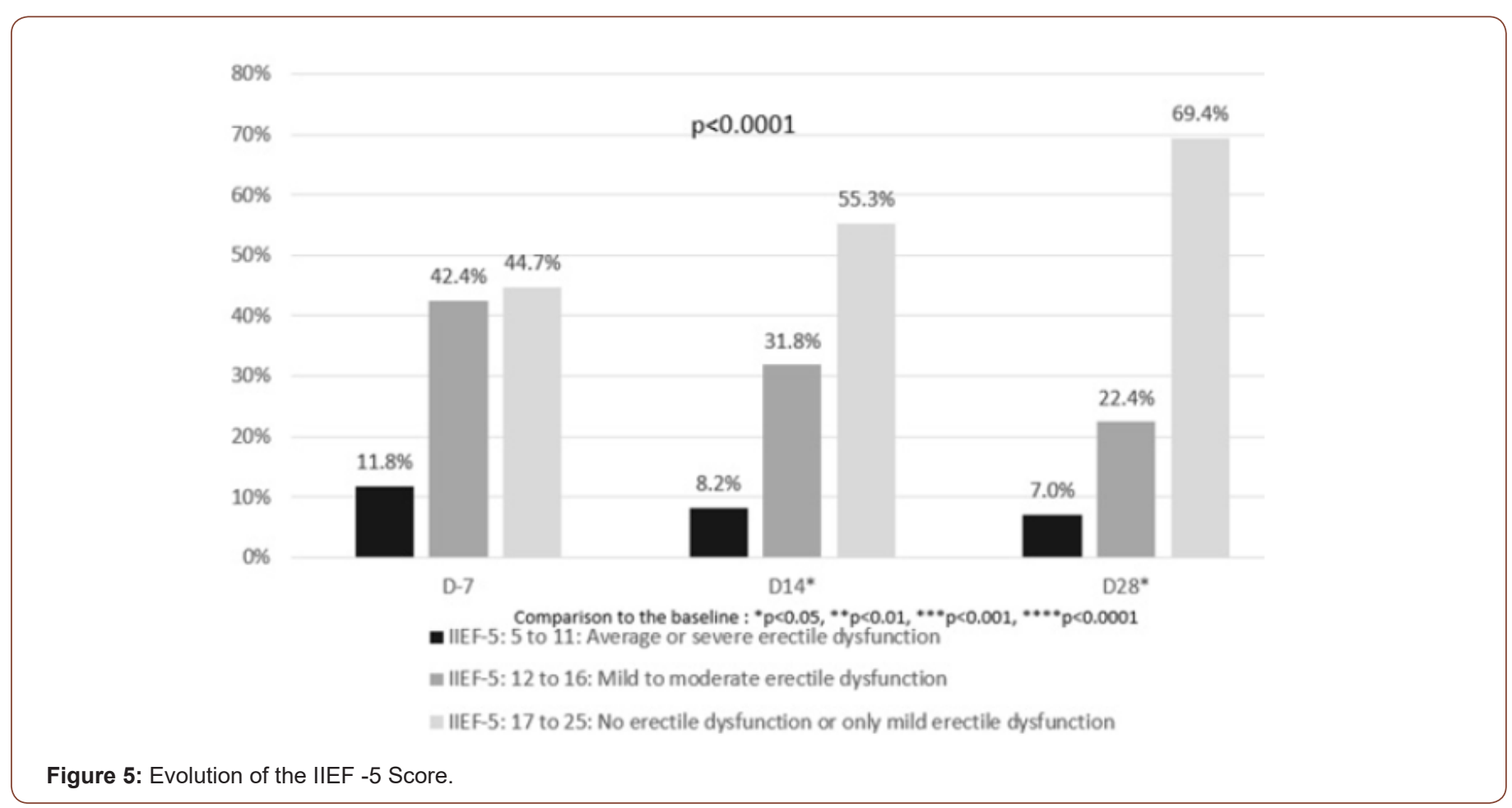


The IIEF-5 score was also significantly improved. The percentage of men having a moderate or severe decrease in erectile function diminished from $11.8 \%$ at the outset to $8.2 \%$ at D14 and $7.0 \%$ at D28 while the percentage of men without a decrease in erectile function or with a slight decrease in erectile function went from $44.7 \%$ at the outset to $53.3 \%$ at D14 and $69.4 \%$ at D28 $(\mathrm{p}<0.0001)$ (Figure 5). On average, the IIEF-5 score increased from $15.6 \pm 3.9$ at the outset to $16.6 \% \pm 5.1$ at D14 and to $17.7 \pm 4.5$ at D28 $(\mathrm{p}<0.0001)$. An improvement in the quality of erections was evidenced by the IIEF- 5 in $71.8 \%$ of the men. This improvement was associated with an improvement in hardness (question 2), of maintaining hardness (question 3), and the duration of the erection (question 4) as reported for $47.1 \%$ of men for these three questions and an increase in their satisfaction (question 5) for $51.8 \%$ of them. Concerning the immediate effect of EnoSTIM ${ }^{\mathrm{TM}}$, only $4.3 \%$ of men reported an increase in the number or quality of their spontaneous erections at the first administration of the product.

\section{Men's Opinions}

As soon as the 14th day, nearly two thirds of men (61.6\%) considered that the quality of their erection was improved, and this percentage reached $66.0 \%$ at D28 while $58.8 \%$ of them declared that their sex live was more satisfying. At the end of the treatment period, more than one in two subjects (54.1\%) were satisfied with the action speed of Enostim ${ }^{\mathrm{TM}}$ and the improvements it brought about, $57.7 \%$ were more confident to engage in sexual activity with a partner and $62.3 \%$ were satisfied globally. Nearly three quarters $(70.6 \%)$ reported themselves disposed to recommend it to a friend with complaints of a decrease in sex function. Among them, $40.0 \%$ reported that their partner was more satisfied with their sexual relations since taking EnoSTIM ${ }^{\mathrm{TM}}$.

\section{Analysis of Effectiveness According to Age, BMI, and Length of Time with Erection Troubles}

Improvement in hardness was comparable at any age, weekly frequency of physical activity, BMI and length of period of erection troubles and no difference was observed as a function of age on the evolution of erection quality and sex life or the number of men that were ready to recommend the product to friends who had complaints of a decrease in sex function. Only two elements were found statistically significant: improvement of IIEF-5 varied significantly according to age with the best results obtained in the range of 50 to 60 years old while the overall satisfaction was more pronounced among subjects whose erection quality had declined within a year or less: $75.8 \%$ vs $53.9 \%$ among the others $(\mathrm{p}<0.01)$. These analyses contribute to show that EnoSTIM ${ }^{\mathrm{TM}}$ is effective regardless of age, BMI, frequency of weekly physical activity, or the length of time of erectile dysfunction but with a great effectiveness for men from 50 to 60 years old and with a more strongly felt satisfaction for men whose complaint has lasted for less than a year.

\section{Discussion}

The results of this study include all well-known methodological limitations of the observational type of study but also carries the advantage of reporting in real time the evolution of men suffering from a decrease in sexual function and their evolution on Enostim ${ }^{\mathrm{TM}}$ as observed in real situations in daily life and more precisely than usual by the use of a secure reporting application on smartphones, eliminating the usual memory biases.

The results of this study cannot be adequately compared to those resulting from tests or observational studies for Inhibitors of Phosphodiesterase type 5 (IPDE-5) such as sildenafil, vardenafil, tadalafil or avanafil which are "as needed" medications, taken before sexual activity since they are not intended for the same purpose; in terms of mechanisms to modulate oxidative stress and chronic vascular inflammatory deviation, but also in terms of observed results (immediate versus ongoing treatment). In the present study, the objective of Enostim ${ }^{\mathrm{TM}}$ is to restore a lasting physiological erectile function while the IPDE-5 supplement the physiological deficit intermittently. The only comparisons of interest could be made on the daily usage of tadalafil $2.5 \mathrm{mg}$ or $5 \mathrm{mg}$ but even then, the comparisons fall short since the patient profiles are quite different and use of tadalafil is characterized by much more severe erectile dysfunctions in respect to IIEF-5 [16-19].

The potential target of Enostim ${ }^{\mathrm{TM}}$ is constituted of men not dealing with erectile dysfunction in terms of frequency or duration but with men whose erections decrease in hardness. It hinges on the IIEF- 5 criteria, notably on question 2 which deals with hardness, but the amplitude of this criterion cannot reach the level of those reached in the tadalafil studies since the IIEF- 5 of patients included in our study is much less altered. In contrast, the change in hardness which is the deficit for which men seek the most counsel, is the most strongly felt by them, even more than the decrease in frequency or duration $[20,21]$, and has shown a clear improvement in our study. Indeed, the average percentage of erections during which the penis was entirely hard (maximum on EHS scale) is practically multiplied by 5 after 3 weeks of product taking. This hardness criterion does not however figure into the studies cited by tadalafil for daily use, probably due to the fact that they did not pursue the same goal.

This improvement essentially with hardness is in accord with the activity of the study's product components which allow for a better circulatory vasodilation and a better filling of the corpora cavernosa under the influence of a permanent increase in NO concentrations. It is important to stress that nearly two thirds of the men reported having an improvement in the quality of their erection, that their sex lives were more satisfying, that they were more confident in engaging in sexual activity with a partner and were generally satisfied. This also reflects the importance men attribute to the quality of penile rigidity and that its strengthening 
is extremely important for their sex lives. The fact that EnoSTIM ${ }^{\mathrm{TM}}$ had such generally satisfying results, testifies to the implications of erection quality in standard of living, even better when the erectile function troubles are relatively recent, should incite quick prescription of this product at the first disappointments before the negative psychological effect of the first failings worsen the situation. Inversely, rediscovering a satisfactory hardness, as indicated in the results, helps make men more confident in engaging in sexual relationships and invokes a positive dynamic that favors success. By influencing hardness, EnoSTIM ${ }^{\mathrm{TM}}$ provides a better satisfaction for men in regard to their sex lives as soon as they begin to be influenced by age, oxidative stress, and chronic vascular inflammation and does so without the risks and inconveniences of IPDE-5. No significant undesirable effect has been reported over the course of this study, testifying to the good tolerability of supplementing with EnoSTIM ${ }^{\mathrm{TM}}$.

\section{Conclusion}

Supplementation with polyphenols from Grape and Apple combined with Saffron (EnoSTIM ${ }^{\mathrm{TM}}$; $600 \mathrm{mg} /$ day) improves the quality of the erection and above all else its hardness and thus contributes to reduce the decline of erectile function in men, improving their sexual function, and increasing their satisfaction with their sex life. This influence on the hardness of the erection is in regard to the vasoactive activity of NO whose production is increased by EnoSTIM ${ }^{\mathrm{TM}}$. It corresponds to a real need in a large portion of the male population whose problems are not tied to the frequency or duration of their erection but at its lack of hardness which corresponds to the first clinical consequences of the appearance of cardiovascular impairment connected to age. By its direct-action mechanism on NO, oxidative stress and vascular inflammatory deviation, this solution is prescribed for the long term, aiming to restore normal function rather than fill an immediate and sporadic need for vasodilation.

\section{Conflict of Interests}

The authors declared the following potential conflict of interest with respect to the research, authorship, and/or publication of this article: FA Allaert is head of health evaluation Chair at BSB \& CEN Nutriment. F Herpin and R Schueller are employees of CEN Nutriment. D Guillemet is director of scientific development of Nexira.

\section{Acknowledgements/Funding}

The authors disclosed receipt of the following financial support for the research, authorship, and/or publication of this article: the study has been funded by Nexira, the sponsor of the study.

\section{References}

1. Feldman HA, Goldstein I, Hatzichristou DG, Krane RJ, Mckinlay JB (1994) Impotence and its medical and psychosocial correlates: results of the Massachusetts Male Aging Study. J Urol 151(1): 54-61.
2. Johannes CB, Araujo AB, Feldman HA, Derby CA, Kleinman KP, et al. (2000) Incidence of erectile dysfunction in men 40 to 69 years old: longitudinal results from the Massachusetts male aging study. J Urol 163(2): 460-463.

3. Montorsi P, Ravagnani PM, Galli S, Rotatori F, Briganti A, et al. (2005) The artery size hypothesis: a macrovascular link between erectile dysfunction and coronary arteru disease. Am J Cardiol 96(12B): 19-23.

4. Burnett and Arthur L (1997) Nitric oxide in the penis: physiology and pathology. J Urol 157(1): 320-4.

5. Agarwal A, Nandipati KC, Sharma RK, Zippe CD, Raina R (2006) Role of oxidative stress in the pathophysiological mechanism of erectile dysfunction. J Androl 27(3): 335-47.

6. Silva FH, Monica FZ, Bau FR, Brugnerotto AF, Priviero FB, et al. (2003) Superoxide anion production by NADPH oxidase plays a major role in erectile dysfunction in middle-aged rats: prevention by antioxidant therapy. J Sex Med 10(4): 960-971.

7. Münzel T, Gori T (2009) Nebivolol: the somewhat-different $\beta$-adrenergic receptor blocker. J Am Coll Cardiol 54(16): 1491-1499.

8. Meller S, Stilp E, Walker CN (2013) The link between vasculogenic erectile dysfunction, coronary artery disease, and peripheral artery disease: role of metabolic factors and endovascular therapy. J Invasive Cardiol 25(6): 313-319.

9. Broekhuizen LN, Van Wijk DF, Vink H (2011) Reduction of monocyte chemoattractant protein 1 and macrophage migration inhibitory factor by a polyphenol-rich extract in subjects with clustered cardiometabolic risk factors. Br J Nutr 106(9): 1416-1422.

10. Shamsa A, Hosseinzadeh H, Molaei M, Shakeri MT and Rajabi O (2009) Evaluation of Crocus sativus L. (shaffron) on male erectile dysfunction: a pilot study. Phytomedicine 16(8): 690-693.

11. Cai T, Morgia G, Carrieri G, Terrone C, Imbimbo C, et al, (2013) An improvement in sexual function is related to better quality of life, regardless of urinary function improvement: results from IDIProst ${ }^{\circledR}$ Gold Study. Arch Ital Urol Androl 85(4): 184-189.

12. Modabbernia A, Sohrabi H, Nasehi AA, Raisi F, Saroukhani S, et al, (2012) Effect of a saffron on fluoxetine-induced sexual impairement in men: randomized double-blind placebo-controlled trial. Psychopharmacology (Berl) 223(4): 381-388

13. Tang FT, Qian ZY, Liu PQ, Zheng SG, He SY, et al, (2006) Crocetin improves endothelium-dependent relaxation of thoracic aorta in hypercholesterolemic rabbit by increasing eNOS activity. Biochem Pharmacol 72(5): 558-565.

14. Intertek Laboratory (2015) France.

15. Mulhal JP, Goldstein I, Bushmakin AG, Joseph C Cappelleri, Kyle Hvidste (2007) Outcome's assessment: Validation of the Erection Hardness Score. The journal of sexual medicine 4(6): 1626-1634

16. Porst H, Gacci M, Büttner H, Henneges C, Boess F (2014) Tadalafil once daily in men with erectile dysfunction: an integrated analysis of data obtained from 1913 patients from six randomized, double-blind, placebo-controlled, clinical studies. Eur Urol 65(2): 455-64.

17. Brock G, Ni X, Oelke M, Mulhall J, Rosenberg M, et al, (2016) Efficacy of Continuous Dosing of Tadalafil Once Daily vs Tadalafil On Demand 
in Clinical Subgroups of Men with Erectile Dysfunction: A Descriptive Comparison Using the Integrated Tadalafil Databases. J Sex Med 13(5): 860-875.

18. Hatzichristou D, d'Anzeo G, Porst H, Buvat J, Henneges, et al, (2015) Tadalafil $5 \mathrm{mg}$ once daily for the treatment of erectile dysfunction during a 6-month observational study (EDATE): impact of patient characteristics and comorbidities. BMC Urol 15: 111.

19. Buvat J, Hatzichristou D, Boess FG, Büttner H, Gehchan N, et al, (2014) Continuation and effectiveness of tadalafil once daily during a 6-month observational study in erectile dysfunction: the EDATE study. Int J Clin Pract 68(9): 1087-1099.

20. King R, Juenemann KP, Levinson IP, Stecher VJ and Creanga DL (2007) Correlations between increased erection hardness and improvements in emotional well-being and satisfaction outcomes in men treated with sildenafil citrate for erectile dysfunction. Int J Impot Res 19(4): 398-406.

21. Claes H, Opsomer RJ, Andrianne R, Vanbelle S, Albert A, et al, (2008) Characteristics and expectations of patients with erectile dysfunction: results of the SCORED study. Int J Impot Res 20(4): 418-424. 